\title{
Seasonal variation in vitamin $D$ status in overweight and obese people of Iraqi and Caucasian descent
}

\author{
W. A. Ahmed, G. A. Rees and A. de Looy \\ University of Plymouth, Drake Circus, Plymouth, PL4 8AA, UK
}

It is well known that vitamin D plays an active role for calcium and phosphorus absorption but there is also growing evidence of an association between vitamin D insufficiency and various chronic diseases ${ }^{(1)}$. Middle Eastern populations are known to be at risk of vitamin $\mathrm{D}$ deficiency due to a diet low in vitamin $\mathrm{D}$ and low sunshine exposure ${ }^{(2)}$. Obesity is also a risk factor for low plasma levels of $25(\mathrm{OH}) \mathrm{D}$ since it is sequestered in body fat ${ }^{(3)}$. This study examined dietary intake of vitamin $\mathrm{D}$ and serum $25(\mathrm{OH}) \mathrm{D}$ in overweight and obese Iraqi people in the UK compared to a Caucasian group at two time points: end of summer (October) and winter (January).

Participants were recruited through Plymouth University via posters and electronic advertisements. Participants were included if they were aged 18 years or more, and had a high percentage of body fat ( $>20 \%$ males and $>30 \%$ females). Exclusion criteria included those taking vitamin D containing supplements, pregnancy or lactation, low or normal percentage body fat or BMI $<25$. Participants completed a screening/ demographic questionnaire and were instructed on the completion of a 3-day diet diary. Body composition was measured using bioelectrical impedance (Tanita, Model TBF-300 M). Height, and weight were also measured at week 0 (October) and again at week 12 (January). Participants were asked not to lose weight during this time and to keep diet and exercise habits unchanged. Fasting blood samples were also taken at weeks 0 and 12 for determination of $25(\mathrm{OH}) \mathrm{D}$ using isotope-dilution liquid chromatography-tandem mass spectrometry ${ }^{(4)}$. A total of 36 participants completed the study (12 Iraqi and 24 Caucasian)

\begin{tabular}{|c|c|c|c|c|c|}
\hline \multirow[t]{2}{*}{ Serum $25(\mathrm{OH}) \mathrm{D}$ and Dietary intake of Vit D } & \multicolumn{2}{|c|}{$\operatorname{Iraqi}(n=12)$} & \multicolumn{2}{|c|}{ Caucasian $(n=24)$} & \multirow[t]{2}{*}{ Difference between Ethnic groups } \\
\hline & Mean & SD & Mean & SD & \\
\hline $25(\mathrm{OH}) \mathrm{D} \mathrm{nmol} / \mathrm{l}(\mathrm{Oct})$ & 25.5 & 11.5 & 59.2 & 24.5 & $P<0.001$ \\
\hline $25(\mathrm{OH}) \mathrm{D} \mathrm{nmol} / \mathrm{l}(\mathrm{Jan})$ & 16.4 & 5.4 & 42.0 & 20.5 & $P<0.001$ \\
\hline Intake of Vit D $\mu \mathrm{g} / \mathrm{d}(\mathrm{Oct})$ & 2.4 & 1.2 & 2.8 & 2.1 & NS \\
\hline Intake of Vit $\mathrm{D} \mu \mathrm{g} / \mathrm{d}$ (Jan) & 1.6 & 1.0 & 2.8 & 2.2 & 0.037 \\
\hline
\end{tabular}

\begin{tabular}{|c|c|c|c|c|}
\hline \multirow[t]{2}{*}{ Range of Serum $25(\mathrm{OH}) \mathrm{D}$} & \multicolumn{2}{|c|}{$\operatorname{Iraqi}(n=12)$} & \multicolumn{2}{|c|}{ Caucasian $(n=24)$} \\
\hline & $n$ & $\%$ & $n$ & $\%$ \\
\hline $25-50 \mathrm{nmol} / \mathrm{l}(\mathrm{Oct})$ & 4 & 33 & 10 & 42 \\
\hline 25-50 nmol/1 (Jan) & 1 & 8 & 12 & 50 \\
\hline$<25 \mathrm{nmol} / 1(\mathrm{Oct})$ & 8 & 67 & 1 & 4 \\
\hline$<25 \mathrm{nmol} / 1$ (Jan) & 11 & 92 & 5 & 21 \\
\hline
\end{tabular}

In conclusion, Iraqi participants had significantly lower serum levels of $25(\mathrm{OH}) \mathrm{D}$ than Caucasians at both time points. Vitamin $\mathrm{D}$ intakes were lower in the Iraqi group than in the Caucasians in January and this, as well as limited sun exposure, will contribute to low serum levels in the Iraqi group. All Iraqi individuals had less than optimum serum $25(\mathrm{OH}) \mathrm{D}$ levels ${ }^{(5)}$ at the end of summer which continued to decline during winter so that all but one had a serum level indicative of deficiency in January $(<25 \mathrm{nmol} / \mathrm{l})$. However, the majority of the Caucasians had low serum levels in January; over $20 \%<25 \mathrm{nmol} / \mathrm{l}$, indicative of deficiency. It is likely that all Middle Eastern immigrants require vitamin D supplementation in the UK.

1. Holick (2004) Am J Clin Nutr 80, 1678S-1688S

2. Mithal et al. (2009) Osteoporosis International 20, 1807-1820.

3. Wartsman et al. (2000) The American Journal of Clinical Nutrition 72, 690-693.

4. Maunsell et al. (2005) Clinical Chemistry 51, 1683-1690.

5. Malabanan et al. (1998) Lancet 351, 805-806. 